\title{
Blockchain-Enabled E-voting
}

By: Nir Kshetri and Jeffrey Voas

Kshetri, Nir and Voas, J. (2018)." Blockchain-Enabled E-voting ", IEEE Software 35(4), 95-99

Made available courtesy of IEEE: https://doi.org/10.1109/MS.2018.2801546

(C) 2018 IEEE. Personal use of this material is permitted. Permission from IEEE must be obtained for all other uses, in any current or future media, including reprinting/republishing this material for advertising or promotional purposes, creating new collective works, for resale or redistribution to servers or lists, or reuse of any copyrighted component of this work in other works.

\begin{abstract}
:
Blockchain-enabled e-voting (BEV) could reduce voter fraud and increase voter access. Eligible voters cast a ballot anonymously using a computer or smartphone. BEV uses an encrypted key and tamper-proof personal IDs. This article highlights some BEV implementations and the approach's potential benefits and challenges
\end{abstract}

Keywords: electronic voting | urban areas | cryptography | blockchain

\section{Article:}

E-voting is among the key public sectors that can be disrupted by blockchain technology. ${ }^{1}$ The idea in blockchain-enabled e-voting (BEV) is simple. To use a digital-currency analogy, BEV issues each voter a "wallet" containing a user credential. Each voter gets a single "coin" representing one opportunity to vote. Casting a vote transfers the voter's coin to a candidate's wallet. A voter can spend his or her coin only once. However, voters can change their vote before a preset deadline. ${ }^{2}$

Here, we argue that blockchains might address two of the most prevalent concerns in voting today: voter access and voter fraud.

The idea is as follows. Eligible voters cast a ballot anonymously using a computer or smartphone. BEV employs an encrypted key and tamperproof personal IDs. For example, the mobile e-voting platform of the Boston-based startup Voatz employs smart biometrics and realtime ID verification. The public ledger ties each cast ballot to an individual voter and establishes a permanent, immutable record. No bad actor can engage in nefarious activities because such activities will be evident on the ledger or corrected by a peer-to-peer consensus network. ${ }^{3}$ To compromise the network, hackers would need to successfully hack most of the blocks (files with transaction records) before new blocks were introduced. ${ }^{3}$ The blockchain's audit trail ensures that no vote has been changed or removed and that no fraudulent and illegitimate votes have been added. ${ }^{4}$ 
Put simply, blockchains enable the creation of tamper-proof audit trails for voting. In this article, we highlight some BEV implementations and the approach's potential benefits and challenges.

\section{Recent Examples}

Initial operational applications of BEV have been for informal, nonbinding, and consultative voting. ${ }^{5}$ For example, in early 2018 , Voatz tested its mobile-phone-based system during events such as student government elections; church-group, nonprofit-organization, and union voting, and subnational political-party events. ${ }^{6}$ The system has also been used in town meetings in Massachusetts. $^{7}$

As Table 1 shows, blockchain-based solutions have been deployed for corporate, community, city, and national voting. For example, in Russia, the city of Moscow's Active Citizen program was launched in 2014 and has more than two million users. ${ }^{8}$ Each year, Moscow neighborhoods hold up to 5,000 to 7,000 meetings. ${ }^{9}$ As of February 2018, 3,450 polls had been conducted using a centralized Oracle database, with 92 million votes cast on diverse subjects such as what color the seats in a new sports arena should be, whether to install driveway access gates in neighborhood yards, and whether to hire a new doorkeeper. ${ }^{10}$ Although these examples don't deal with political offices, blockchains could be tailored for that purpose.

Table 1. Blockchain-based solutions deployed for voting at the community, city, and national levels.

\begin{tabular}{|c|c|c|}
\hline Setting & The context & Remarks \\
\hline $\begin{array}{l}\text { The city of Moscow's } \\
\text { Active Citizen program }\end{array}$ & $\begin{array}{l}\text { In December } 2017 \text {, the program started } \\
\text { using a blockchain for voting and to make } \\
\text { the voting results publicly auditable. Each } \\
\text { question discussed by the community and } \\
\text { put up for voting is moved to the e-voting } \\
\text { system using a blockchain. After the voting } \\
\text { is complete, the results are listed on a } \\
\text { ledger containing all the previous polls. }\end{array}$ & $\begin{array}{l}\text { The most popular polls were reported to } \\
\text { have } 137,000 \text { to } 220,000 \text { participants. }{ }^{10} \text { In } \\
\text { one such case on the Ethereum platform, } \\
\text { citizens indicated their preferences for } \\
\text { temporary relocation if the building in } \\
\text { which they were living would be } \\
\text { demolished and replaced by a better } \\
\text { building. The platform reached a peak of } \\
\text { approximately } 1,000 \text { transactions per } \\
\text { minute. It's not clear whether the platform } \\
\text { can handle the volume if a higher } \\
\text { proportion of Moscow's } 12 \text { million citizens } \\
\text { participate in the voting. }\end{array}$ \\
\hline $\begin{array}{l}\text { The South Korean } \\
\text { province of Gyeonggi-do's } \\
\text { community projects }\end{array}$ & $\begin{array}{l}\text { The province used a blockchain-based } \\
\text { voting system to gather votes on } \\
\text { community projects. } 9,000 \text { residents voted. }\end{array}$ & $\begin{array}{l}\text { The Korean financial-technology startup } \\
\text { Block developed the blockchain platform. }\end{array}$ \\
\hline $\begin{array}{l}\text { The annual general } \\
\text { meeting of the Estonian } \\
\text { tech company LVH Group }\end{array}$ & $\begin{array}{l}\text { Shareholders can log in using their verified } \\
\text { national online ID and vote at the meeting. }\end{array}$ & $\begin{array}{l}\text { The voting system issues voting-right } \\
\text { assets and voting-token assets to } \\
\text { shareholders. A user can spend voting } \\
\text { tokens to vote on meeting agenda items if } \\
\text { that user owns the related voting-right } \\
\text { asset. Nasdaq designed the system. }\end{array}$ \\
\hline $\begin{array}{l}\text { Sierra Leone's March } \\
2018 \text { general elections }\end{array}$ & $\begin{array}{l}\text { Swiss startup Agora carried out tallying in } \\
\text { two districts. After the voting, a team of } \\
\text { accredited observers from different } \\
\text { locations manually entered approximately } \\
400,000 \text { ballots into Agora's blockchain } \\
\text { system. }\end{array}$ & $\begin{array}{l}\text { This test was considered a partial } \\
\text { deployment of a blockchain. }{ }^{11} \text { The } \\
\text { elections were only verified by blockchain, } \\
\text { not blockchain powered. Agora provided } \\
\text { an independent vote count, which was } \\
\text { compared with the main tally. }\end{array}$ \\
\hline
\end{tabular}


Furthermore, many Moscow residents don't have time to attend face-to-face meetings. So, meetings have moved to the Digital Home online platform. In December 2017, residents began using a blockchain to vote, and the results were publicly auditable. ${ }^{8}$ City officials believed that neighbors should have a convenient environment in which to influence their living conditions. The officials also believed that a blockchain would increase trust between citizens and government. ${ }^{12}$ Each question discussed by the community is moved to BEV. After the polling is finished, the results are provided. ${ }^{9}$

To assess BEV's trustworthiness, the city of Moscow commissioned the accounting firm PwC to conduct an audit. ${ }^{10} \mathrm{PwC}$ looked at the possibility that the polling's outcome could be manipulated by internal employees and external attacks. The audit found no reason to be concerned for polls that involved more than 300,000 votes.

In March 2017, the South Korean province of Gyeonggi-do employed a BEV system to vote on the Ddabok Community Support Project. ${ }^{13}$ Nine-thousand residents voted using a blockchain platform developed by the Korean financial-technology startup Block that included smart contracts. The votes, results, and other relevant data were stored in a blockchain. No management or central authority was involved in this process. ${ }^{14}$ This was the first time South Korea applied such a technology.

Shareholders of the Estonian technology company LVH Group who are Estonian citizens or Estonian e-residents can now use BEV to make corporate-governance-related decisions. ${ }^{15}$ They can $\log$ in using their verified national online ID and vote at LVH's annual general meeting. Estonia's e-residency platform authenticates e-resident shareholders. ${ }^{16}$ Estonia plans to adopt blockchains in a range of areas such as an e-residency project (which allows foreign citizens to establish a business within Estonian jurisdiction) and healthcare (securing health data storage and allowing real-time monitoring of patient conditions). ${ }^{17}$

In Sierra Leone's March 2018 general elections, Swiss blockchain startup Agora provided a partial tally of election results. ${ }^{11}$ Agora was one of the accredited observers that provided an independent count for comparison. Agora described Sierra Leone's elections as a "use case" rather than a "full implementation" of BEV. ${ }^{18}$

Finally, Nasdaq has built and operated four web-based user interfaces for BEV. ${ }^{15}$ A BEV system issues voting-right assets and voting-token assets for each shareholder in a company. A user can spend voting tokens to cast votes on each meeting agenda item if that user owns the related voting-right asset.

\section{Opportunities and Benefits}

BEV provides the following opportunities and benefits.

To address voter tampering, blockchains generate cryptographically secure voting records. Votes are recorded accurately, permanently, securely, and transparently. ${ }^{5}$ So, no one can modify or manipulate votes. ${ }^{19}$ Furthermore, blockchains preserve participants' anonymity while still being 
open to public inspection. Although nothing is totally secure, tampering is nearly impossible with blockchains.

BEV might promote more voter participation. For instance, corporate annual general meetings can be costly events with low shareholder participation. With increasing cross-border investments, companies face pressure to increase investor engagement. BEV is a flexible solution that enables secure, cost-effective voting to facilitate shareholder participation and voting from a distance. ${ }^{20}$

Also, improved identity verification can help increase access and participation. For example, according to a federal court in Texas, 608,470 registered voters lacked verification identification. ${ }^{21}$ Approximately 11 percent of US citizens lack government-issued photo identification cards. ${ }^{21}$ BEV can improve this situation. For instance, Voatz accepts 10 different official documents including driver's licenses, state IDs, and passports to verify voter identity. ${ }^{22}$

BEV can increase the speed with which votes are tallied. For example, Agora reported that it published election results on its website five days before the official manual counts ended. ${ }^{16}$

BEV can eliminate ambiguities. For example, in the 2017 Virginia House of Delegates election, the winner was chosen from paper ballots placed in a bowl. One vote initially wasn't counted because that voter made confusing marks on the ballot. ${ }^{6}$ Such ambiguity is less likely to arise with BEV.

BEV can promote greater transparency and clarity to voters. As of 2017, 23 countries in had adopted online voting. ${ }^{23}$ Current online-voting processes might be complicated for some voters. It's not easy to know whether a vote was cast as intended or whether it was counted as cast. ${ }^{23}$ As we already noted, blockchain results are publicly auditable.

Some security systems in electronic- and online-voting platforms were possibly developed decades ago and are vulnerable to tampering. ${ }^{24}$ Consider the WINVote touchscreen machines made by Advanced Voting Solutions, which went out of business in $2015 .^{25}$ WINVote machines were used in the 2016 US elections even though they hadn't had a security patch since April 2014. A security expert found that anyone within a half-mile of a voting machine could have altered votes without detection. Blockchains' decentralized nature makes attacks more difficult.26

Finally, with BEV, individual votes will be publicly available, while voters are masked behind an encrypted key. This offers greater privacy and security than traditional ballot boxes and could reduce voter suppression. Bad actors can't identify voters and therefore can't target them. ${ }^{3}$

\section{Challenges}

Governments and other stakeholders will need to address several major challenges before blockchains see widespread use for e-voting. Although blockchains are good at providing security and accuracy, public confidence and trust are necessary ingredients for BEV's success. 
Blockchains' complexity might hinder mainstream public acceptability of BEV.${ }^{27}$ Broadband access and digital user skills are also concerns.

In 2016, the nonprofit Democracy Earth Foundation used a blockchain to give Colombian expatriates a voice in the 2016 peace plebiscite that was conducted to ratify the agreement to terminate the conflict between the Colombian government and FARC guerillas. ${ }^{28}$ According to the foundation, a main challenge in the deployment blockchain is the technology's immaturity.

Let's now consider software quality. Estimates have suggested that, on average, there are from 15 to 50 defects per 1,000 LOC. ${ }^{29}$ For Ethereum, the blockchain-based distributed-computing platform used by Moscow's Active Citizen program (which features smart contracts), the number might be twice that. This might be attributed to Ethereum's immaturity. The Economist quoted a blogger who said that Ethereum contracts are "candy for hackers." 29 Also, sufficient observations haven't yet been accumulated to determine blockchain-based platforms' scalability.

Traditional voting emphasizes the authority of the state. BEV emphasizes voter transparency. The BEV process is transparent, decentralized, and bottom-up. BEV might not perform well in a society whose culture and values exhibit low compatibility with these values. ${ }^{27}$

Also, blockchains require much energy to perform authentication and validation, and they're slow. So, using them for national e-voting might not be practical yet.

Finally, BEV will shift power away from central actors such as electoral authorities and government agencies. ${ }^{27}$ Thus, the technology is likely to face resistance from political leaders who benefit from the status quo. ${ }^{28}$

Blockchain technology is currently in a nascent state. There haven't been enough distributedledger-technology and blockchain-based applications to sufficiently evaluate whether this technology is superior to current voting systems.

No full implementation of BEV for a national election has occurred yet. However, we argue that $\mathrm{BEV}$ has a future in elections and might transform voting.

Political violence related to elections has been common in Africa and other developing countries. $\mathrm{BEV}$ can ensure security and transparency and reduce electoral violence. It can also produce more mathematically accurate election results. Because BEV doesn't require management from a central authority, voting-related costs will decrease. Finally, BEV should reduce the cost of paper-based elections and increase voter participation.

\section{References}

1. J. Demuro, "Here Are the 10 Sectors That Blockchain Will Disrupt Forever," TechRadar Pro, 16 Jan. 2018; https://www.techradar.com/news/here-are-the-10-sectors-that-blockchain-willdisrupt-forever. 
2. B. Dickson, "Blockchain Tech Could Fight Voter Fraud - and These Countries Are Testing It," VentureBeat, 22 Oct. 2016; https://venturebeat.com/2016/10/22/blockchain-tech-could-fightvoter-fraud-and-these-countries-are-testing-it.

3. J. Hall, "Can Blockchain Technology Solve Voting Issues?," Bitcoin Magazine, 7 Mar. 2018; https://www.nasdaq.com/article/can-blockchain-technology-solve-voting-issues-cm931347.

4. A. Sandre, "Blockchain for Voting and Elections," Hackernoon, 14 Jan. 2018; https://hackernoon.com/blockchain-for-voting-and-elections-9888f3c8bf72.

5. G. Prico, "Sierra Leone Pilots Blockchain-Based Voting for Political Elections," 22 Mar. 2018; https://www.nasdaq.com/article/sierra-leone-pilots-blockchain-based-voting-for-politicalelections-cm938309.

6. B. Miller, "Blockchain Voting Startup Raises \$2.2M," Government Technology, 8 Jan. 2018; http://www.govtech.com/biz/Blockchain-Voting-Startup-Raises-22M.html.

7. A. Perala, "Voatz Raises \$2.2 Million in Seed Funding," Mobile ID World, 9 Jan. 2018; https://mobileidworld.com/voatz-seed-funding-901093.

8. M. Hochstein, "Moscow's Blockchain Voting Platform Adds Service for High-Rise Neighbors," CoinDesk, 15 Mar. 2018; https://www.coindesk.com/moscows-blockchain-votingplatform-adds-service-for-high-rise-neighbors.

9. "Digital Home Blockchain Voting System, Active Citizen in Moscow Opens," BitccoinExchangeGuide.com; https://bitcoinexchangeguide.com/digital-home-blockchainvoting-system-active-citizen-in-moscow-opens.

10. M.D. Castillo, "Russia Is Leading the Push for Blockchain Democracy," CoinDesk, 2018; https://www.coindesk.com/russias-capital-leading-charge-blockchain-democracy.

11. B. Kimathi, "Why You Shouldn't Get Carried Away by Sierra Leone's Blockchain Elections," Crypto-Lines, 13 Mar. 2018; https://crypto-lines.com/2018/03/13/blockchainelections.

12. S. Holder, "Can the Blockchain Tame Moscow's Wild Politics?," CityLab, 22 Dec. 2017; https://www.citylab.com/life/2017/12/can-the-blockchain-tame-moscows-wild-politics/547973.

13. "A South Korean Province Used Blockchain Tech for Resident Voting," CCN.com, 8 Mar. 2017; https://www.ccn.com/south-korean-province-used-blockchain-tech-resident-voting.

14. "South Korea Uses Blockchain Technology for Elections," KryptoMoney, 2 May 2017; https://kryptomoney.com/south-korea-uses-blockchain-technology-for-elections.

15. S. Waterman, "Nasdaq Says Estonia E-Voting Pilot Successful," Cyber-Scoop, 25 Jan. 2017; https://www.cyberscoop.com/nasdaq-estonia-evoting-pilot. 
16. K. Aasmae, "Why Ripples from this Estonian Blockchain Experiment May Be Felt around the World," ZDNet, 14 Apr. 2016; https://www.zdnet.com/article/why-ripples-from-thisestonian-blockchain-experiment-may-be-felt-around-the-world.

17. "How Estonia Brought Blockchain Closer to Citizens: GovTech Case Studies," Cointelegraph, 7 Mar. 2017; https://cointelegraph.com/news/how-estonia-brought-blockchaincloser-to-citizens-govtech-case-studies.

18. D. Finnan, "Sierra Leone's Electoral Commission Distances Itself from Use of Blockchain during Polls," RFI, 18 Mar. 2018; http://en.rfi.fr/africa/20180319-sierra-leones-electoralcommission-distances-itself-use-blockchain-during-polls.

19. K. Leary, "Blockchain Might Be about to Change the Way We Vote," World Economic Forum, 13 Sept. 2017; https://www.weforum.org/agenda/2017/09/blockchain-could-be-about-tochange-how-you-vote, 2017.

20. R. DeMarinis, "Is Blockchain the Answer to E-Voting? Nasdaq Believes So," Nasdaq, 23 Jan. 2017; http://business.nasdaq.com/marketinsite/2017/Is-Blockchain-the-Answer-to-E-votingNasdaq-Believes-So.html.

21. S. Horwitz, "Getting a Photo ID So You Can Vote Is Easy. Unless You're Poor, Black, Latino or Elderly," Washington Post, 23 May 2016; https://www.washingtonpost.com/politics/courts law/getting-a-photo-id-so-you-can-vote-iseasy-unless-youre-poor-black-latino-or-elderly/2016/05/23/8d5474ec-20f0-11e6-8690f14ca9de2972 story.html?noredirect5on\&utm term5.233edc07152e.

22. E. Kuebler, "Making Voting, Elections Both Secure and Accessible with Blockchain Technology," Bitcoin Magazine, 11 Jan. 2018; https://bitcoinmagazine.com/articles/makingvoting-elections-both-secure-and-accessible-blockchain-technology.

23. D. Lohrmann, "Can Blockchain Technology Secure Your Vote?," Government Technology, 29 Apr. 2017; http://www.govtech.com/blogs/lohrmann-on-cybersecurity/can-blockchaintechnology-secure-your-vote.html.

24. P. Marley and J. Stein, "Russians Tried to Hack Election Systems of 21 States in 2016, Officials Say," USA Today, 22 Sept. 2017; https://www.usatoday.com/story/news/nationnow/2017/09/22/wisconsin-one-20-states-targeted-russian-hacking-elections-systems$\underline{2016 / 694719001 .}$.

25. K. Zetter, "Virginia Finally Drops America's 'Worst Voting Machines," Wired, 17 Aug. 2015; https:/www.wired.com/2015/08/virginia-finally-drops-americas-worst-voting-machines.

26. B. Barrett, “America's Electronic Voting Machines Are Scarily Easy Targets," Wired, 2 Aug. 2016; https://www.wired.com/2016/08/americas-voting-machines-arent-ready-election. 
27. P. Boucher, What If Blockchain Technology Revolutionised Voting?, European Parliamentary Research Service, 2016;

http://www.europarl.europa.eu/thinktank/en/document.html?reference5EPRS_ATA(2016)58191 $\underline{8}$.

28. C. van Ooijen, "How Blockchain Can Change Voting: The Colombian Peace Plebiscite," Forum Network, 20 Dec. 2017; https://www.oecd-forum.org/users/76644-charlotte-vanooijen/posts/28703-how-blockchain-can-change-voting-the-colombian-peace-plebiscite.

29. "Not-So-Clever Contracts," Economist, 28 July 2016; https://www.economist.com/news/business/21702758-time-being-least-human-judgment-stillbetter-bet-cold-hearted. 